\title{
Removal of monodisperse liquid aerosols by using the polysulfone membrane filters
}

\author{
Hsiao-Lin Huang ${ }^{\mathrm{a}}$, Da-Ming Wang ${ }^{\mathrm{a}, \mathrm{b}}$, Se-Tsung Kao ${ }^{\mathrm{b}}$, \\ Shinhao Yang ${ }^{\mathrm{c}, *}$, Yi-Chin Huang ${ }^{\mathrm{d}}$ \\ ${ }^{a}$ Department of Occupational Safety and Hygiene, Chia Nan University of Pharmacy \& Science, Tainan 717, Taiwan, ROC \\ ${ }^{\mathrm{b}}$ Department of Chemical Engineering, National Taiwan University, Taipei 106, Taiwan, ROC \\ ${ }^{\mathrm{c}}$ Department of Leisure and Recreation Management, Toko University, 51 University Rd., Sec. 2, Pu-tzu City, Chia Yi County 613, Taiwan, ROC \\ ${ }^{\mathrm{d}}$ Planning and Evaluation Division, National Science Council, Taipei 106, Taiwan, ROC
}

Received 15 May 2006; received in revised form 14 August 2006; accepted 16 August 2006

\begin{abstract}
Polymer membrane filters are extensively used for sampling and collecting aerosols. This work explores the aerosol penetration of the polysulfone (PSF) membrane filters using monodisperse liquid aerosols. Three concentration-casting polysulfone solutions (15, 20 and $25 \%)$ were utilized to yield PSF membrane filters with variously sized pores. Additionally, the effects of various factors, including the species of the aerosol (dioctyl phthalate and potassium chloride), the size of the aerosol $(0.03-0.5 \mu \mathrm{m})$, the face velocity $(5,10$ and $20 \mathrm{~cm} / \mathrm{s})$ and the relative humidity $(30,50$ and $70 \%$ ), on the aerosol penetrations, were estimated.

Experimental results indicate that the penetrations of DOP liquid aerosols through 15, 20 and 25\% PSF membrane filters with "Boltzmann charge equilibrium" are 3.1-9.1, 1.5-3.7 and 0.6-1.4\%, respectively. The most penetrating size of the PSF membrane filters was around $0.05 \mu m$. Our results further demonstrate that penetration through PSF membrane filters fell as the concentration-casting solution increased, because the pore size of the PSF membrane filters declines as the concentration of the casting solution rises. Moreover, the penetration of solid aerosols through PSF membrane filters exceeds that of liquid aerosols. Penetration through the PSF membrane filters increases obviously with the flow rate when aerosol smaller than $0.21 \mu \mathrm{m}$. When aerosol larger than $0.3 \mu \mathrm{m}$, the variations of penetration through the PSF membrane filters become smaller at different flow rates. The relative humidity does not influence the performance of the PSF membrane filters. Results of this study demonstrate that the $25 \%$ PSF membrane filter has a larger $q_{\mathrm{F}}$ than the 15 and $20 \%$ PSF membrane filters.
\end{abstract}

(C) 2006 Elsevier B.V. All rights reserved.

Keywords: Aerosol penetration; Polysulfone membrane filters; Face velocity; Relative humidity; Quality factor

\section{Introduction}

Filtration is the most effective and reliable approach for collecting particulate matters from gas stream. Filters used to sample or collect aerosols can generally be identified as fibrous filters, fabric filters and membrane filters. The function of the various filters is determined by their structure, pore size, packing fraction, fiber diameter, filter thickness, felting methods and the air resistance across the filter. Membrane filters have been extensively applied to sample or collect particles in the fields of occupational hygiene and environmental hygiene [1-4], because they can tolerate high pressure and filter at high face velocity.

\footnotetext{
* Corresponding author. Tel.: +886 5 3822886\#684; fax: +886223661544.

E-mail address: shinhaoyang@ntu.edu.tw (S. Yang).
}

Additionally, the particles collected on the membrane filters can be weighed, chemically analyzed [5] and physically observed by electronic microscopy.

The membrane filters were divided into two groups. The first was of capillary pore membrane filters. The pores in such filters are cylindrical, with an almost uniform diameter, and most are perpendicular to the surface of the filter. The other membrane filters have different pore sizes and the paths through the pores inside the filter are crooked. Earlier investigations of the filtration characteristics of membrane filters have focused on the filtration performance of membrane filters with uniformly sized pores. Spurny and Pich [6] and Manton [7,8] established that the main aerosol collecting mechanisms of the Nuclepore membrane filters are interception, impaction and diffusion. Spurny et al. $[9,10]$ found that the filtration properties of the membrane filters are related to particle size, pore size, pressure 
drop, porosity of the filter and the temperature. Some studies $[11,12]$ have developed the theoretical relationship among the sizes of the capillary pores, the particle sizes and the filtration efficiencies. Montassier et al. [13] experimentally investigated the aerosol penetration and pressure drop of one capillary pore membrane filter using radioactive aerosols. Sioutas et al. [14] examined the loading behavior of the Nuclepore membrane filters. Yamamoto et al. [15] also characterized the time course shift in penetration through capillary polycarbonate pore membrane filters for relatively short filtration periods.

Recently, polymer membrane filters have been commercially used in aerosol sampling and air purification, because they have the widest possible range of pore sizes, supporting high pressure and filtering at high face velocity. Polysulfone (PSF) is a polymer material. The chemical and physical attributes of PSF, including good thermal and chemical stability, mechanical strength and excellent oxidative resistance, make it a preferred material for use as a membrane substrate. Traditionally, PSF membrane filters have been widely utilized in water ultrafiltration systems [16,17], gas separation [18], ion-exchange membranes in electro-membrane processes, including electrodialysis and polymer electrolyte membrane electrolysis $[19,20]$. However, PSF membrane filters have seldom been employed in filtering and sampling aerosols. Accordingly, this work examines the penetration of aerosol through PSF membrane filters formed from solutions of various concentrations of PSF. Very few investigations $[21,22]$ have examined the penetration of liquid aerosols through polymer membrane filters. Hence, this work elucidates the penetration of submicron liquid aerosols through PSF membrane filters. Moreover, the PSF membrane filters were belong to the various cylindrical filters [23]. Pervious studies always investigated the filtration characteristics of the capillary pore membrane filters. Thus, this work could also explore the filtration performance of the various cylindrical filters with liquid aerosol. The effects of aerosol type, face velocity and relative humidity on the penetration through PSF membrane filters were also considered.

\section{Experimental materials and methods}

\subsection{Tested filters}

A PSF (Udel P-3500, AMOCO Performance Products Inc.) was utilized herein to form membrane filters. $\mathrm{N}$ methylpyrrolidinone (reagent grade) was the solvent, and the distilled water was applied as the nonsolvent. PSF was dissolved in the above solvent mixture to yield the casting solution at a specified temperature. The degassed casting solution was cast onto a preheated glass plate to a thickness of $300 \mu \mathrm{m}$, using a preheated Gardner knife. The newly formed membrane was immediately immersed in a distilled water coagulation bath at the same temperature, at which it was held for at least 1 day. The obtained membranes were peeled off and air-dried completely at the ambient temperature. This work used casting solutions at three concentrations (15, 20 and 25\%) to yield the PSF membrane filters. The pores of the membrane filters typically decrease with the polymer concentration [24]. Hence, these three PSF membrane filters can be employed to elucidate the effect of pore size on aerosol penetration through the PSF membrane filters. Table 1 summarizes the basic characteristics of the PSF membrane filters. The pore size of the PSF membrane filter really decreases with the PSF concentration of the casting solution increased.

Three PSF membrane filters were belong to the various cylindrical membrane filters. The Nuclepore filter (Isopore membrane) was the capillary pore membrane filter. Thus, we can find the difference of the filtration characteristics between various cylindrical membrane filter and capillary pore membrane filter. Besides, the penetration through the Isopore membrane selected in this work is in the moderate penetration range (Spurny et al. [9,10]; Liu et al. [22,25]). Thus, we can understand the degree of the filtration characteristics of these three polysulfone membrane filters. Therefore, a manufactured capillary pore membrane filter with $0.6 \mu \mathrm{m}$ pore size (Isopore membrane filter, Millipore Ltd.) was also used for comparison, to elucidate for the performance of the PSF membrane filters. The pore size of this Isopore membrane filter $(0.6 \mu \mathrm{m})$ is the moderate pore size of the available capillary pore membrane filters. The porosity of the selected membrane was in the range of 5-20\%. And the porosity of the selected membrane and the other Isopore membranes were also generated in the same range. Table 1 also presents the properties of the capillary pore membrane filter. In this work, the diameter of each filter was controlled at $47 \mathrm{~mm}$.

\subsection{Overall porosity}

The porosity of the PSF membrane filters is calculated using the following equation.

porosity $=\frac{V_{\mathrm{m}}-V_{\mathrm{p}}}{V_{\mathrm{m}}} \times 100 \%$,

where $V_{\mathrm{m}}$ represents the bulk volume of the membrane and $V_{\mathrm{P}}$ is the polymer volume. $V_{\mathrm{m}}$ is determined by multiplying the membrane area by its thickness. A thickness gauge was used

Table 1

Characteristics of PSF membrane filters

\begin{tabular}{|c|c|c|c|c|}
\hline Type & Fiber material & Measured weight of filter $\left(\mathrm{g} / \mathrm{m}^{2}\right)$ & Filter thickness (mm) & Porosity (\%) \\
\hline $15 \% \mathrm{PSF}$ & Polysulfone & 16.4 & 0.03 & 55.9 \\
\hline $20 \% \mathrm{PSF}$ & Polysulfone & 19.2 & 0.03 & 48.4 \\
\hline $25 \% \mathrm{PSF}$ & Polysulfone & 22.1 & 0.03 & 40.6 \\
\hline Isopore membrane filter & Polycarbonate & 8.9 & 0.001 & $5-20$ \\
\hline
\end{tabular}




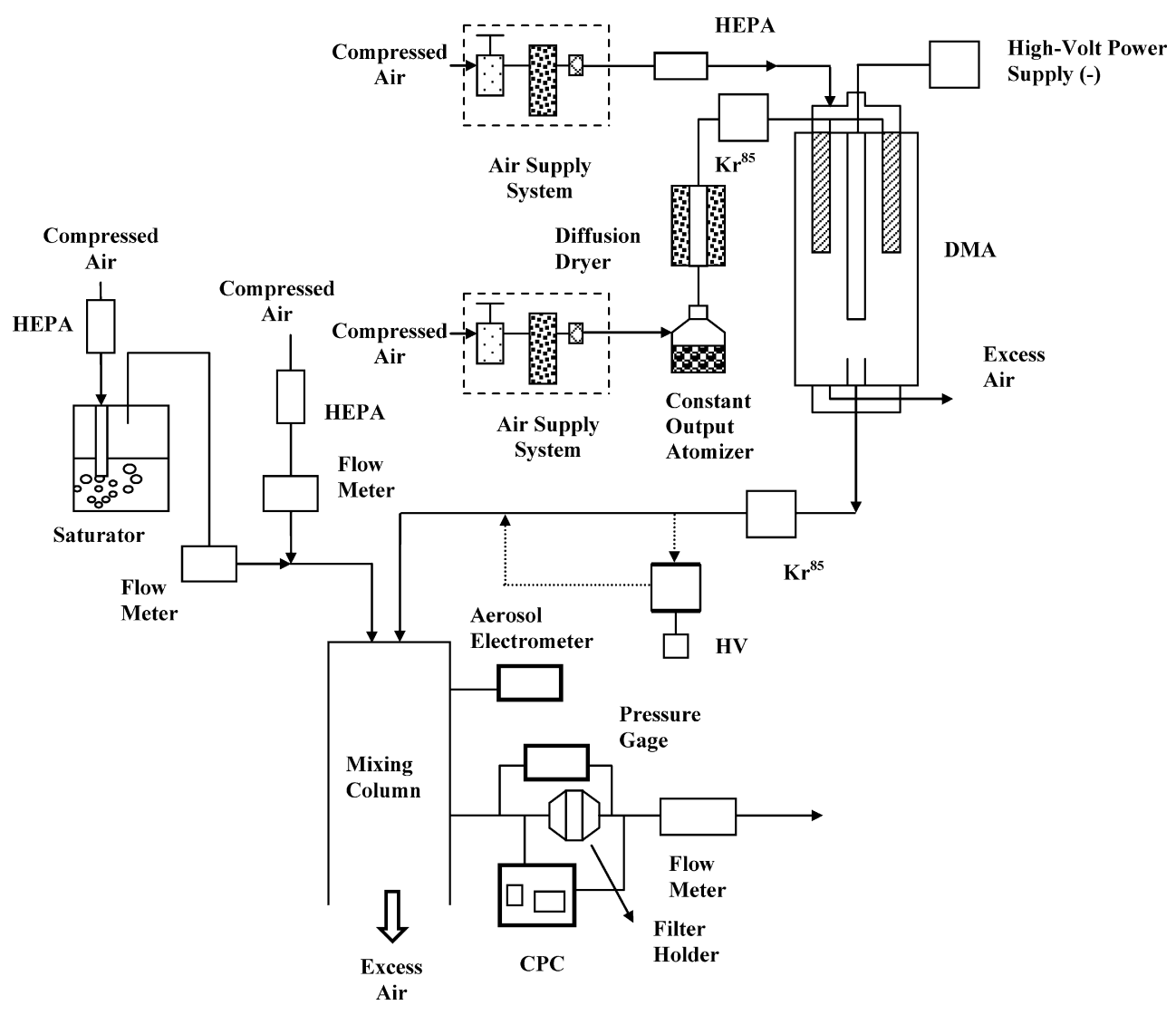

Fig. 1. Schematic diagram of the experimental system.

to measure the membrane thickness. The volume occupied by the polymer $\left(V_{\mathrm{P}}\right)$ can be determined as $W_{\mathrm{m}} / \rho_{\mathrm{p}}$, where $W_{\mathrm{m}}$ is the weight of the membrane and $\rho_{\mathrm{p}}$ is the density of the polymer and has a value of $1.24 \mathrm{~g} / \mathrm{cm}^{3}$ for PSF. Table 1 describes the porosity and the basic characteristics of the PSF membrane filters.

\subsection{Aerosol generation system}

Fig. 1 presents the experimental set up for the aerosol penetration test of the PSF membrane filters. It comprises a Constant Output Atomizer (aerosol generator), a Differential Mobility Analyzer, a neutralizer, a mixing column, a filter holder, a tested filter, an aerosol electrometer, a condensation particle counter used to sample the aerosol concentrations upstream and downstream of the filter and a pressure gauge to measure the pressure drop across the filter and a flow meter.

Dioctyl phthalate (DOP) and potassium chloride $(\mathrm{KCl})$ were selected as the liquid and solid test aerosols. These two aerosols were often used as the liquid and solid aerosols in several researches [25-29]. The test aerosols were generated in a polydisperse state using a Constant Output Atomizer (model 3076, TSI Inc.). Then, the dried and neutralized polydisperse aerosol was electrically classified using a Differential Mobility Analyzer (DMA, model 3080, TSI Inc.), to yield monodisperse, singly charged aerosols in the submicrometer-sized range from 0.03 to $0.5 \mu \mathrm{m}$. The monodispersity and aerosol concentration of the generated particles were measured using a Scanning Mobility Particle Sizer (SMPS, model 3936, TSI Inc.). The geometric standard deviation (GSD) of these generated particles, based on particle counts varied from 1.10 to 1.15 . The DOP aerosol concentrations are about $5 \times 10^{3}$ particles $/ \mathrm{cm}^{3}$. The $\mathrm{KCl}$ aerosol concentration are about $4 \times 10^{3}$ particles $/ \mathrm{cm}^{3}$. The aerosols from the DMA passed through a $\mathrm{Kr}-85$ radioactive source (model 3077, TSI Inc.), which neutralized them to the Boltzmann charge equilibrium. Then, the tested aerosol was flowed into the mixing column, in which it was mixed with the diluted clean air. An aerosol electrometer (model 3068, TSI Inc., $\mathrm{MN}$ ) was applied to monitor the neutralization of the charge of the aerosol in the mixing column. The diluted aerosol flow was drawn through the filter holder by using the flow meter and the pump.

\subsection{Measuring penetration of aerosol}

The penetration through the PSF membrane filters was measured using a condensation particle counter (CPC, model 3022A, TSI Inc.), which measured the aerosol concentrations upstream and downstream of the tested filter. The pressure drop across the tested filter was measured using a pressure gauge (Model 2000$50 \mathrm{CM}$, Dwyer Instruments Inc.) during the period of testing. The face velocity through the tested filter was controlled using a flow meter and a pump. The testing face velocities were varied from 5 to $20 \mathrm{~cm} / \mathrm{s}$.

Aerosol penetrations of $0.03-0.5 \mu \mathrm{m}$ using DOP monodisperse aerosols without any filter were sampled to ensure that aerosol removal occurs only on the filter surface and not on the 


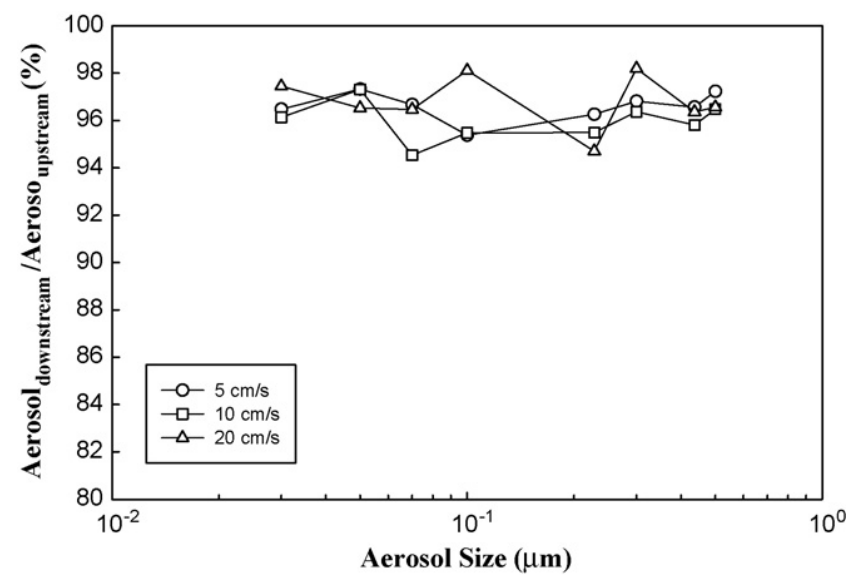

Fig. 2. Evaluation of aerosol losses through the test chamber and filter holder.

holder or any part of the test chamber. Aerosol concentrations upstream and downstream of the filter holder were immediately sampled using a CPC. Penetration tests were undertaken at face velocity of 5, 10 and $20 \mathrm{~cm} / \mathrm{s}$. Results displayed in Fig. 2, clearly display that losses of submicron aerosols through the holder are very small $(<5 \%)$, verifying that aerosol removal could only occur across the tested filter.

\subsection{Relative humidity control system}

This work considered the effect of relative humidity $(\mathrm{RH})$ on the filtration characteristics. Three RHs were used in this work. The RH of the aerosol-flow stream was modified by changing the ratio of the flow rate of the dry gas stream to that of the humidified gas stream generated by the water vapor saturator. The final RH of the aerosol-flow stream was measured using a Q-Trak Plus (Model 8552, TSI Inc.). Three relative humidity conditions for experiments were 30,50 and $70 \%$ in this study.

\subsection{Quality factor}

A good filter provides the highest collection efficiency with the lowest pressure drop. A useful index of quality for various filters is the quality factor, $q_{\mathrm{F}}$, defined as [30]

$q_{\mathrm{F}}=\frac{\ln (1 / P)}{\Delta p}$

where $P$ represents the particle penetration, and $\Delta p$ is the pressure drop across the filter. A better filter has a larger $q_{\mathrm{F}}$. Values of $q_{\mathrm{F}}$ can be compared only when the face velocity and size of the test particle are held constant.

\section{Results and discussion}

\subsection{Pressure drop across the PSF membrane filters}

Fig. 3 plots the pressure drop across the three PSF membrane filters $(15,20$ and $25 \%$ PSF) against the sampled face velocity. The pressure drop increases with the face velocity, indicating that the airflow through the tested filters is laminar. The pressure

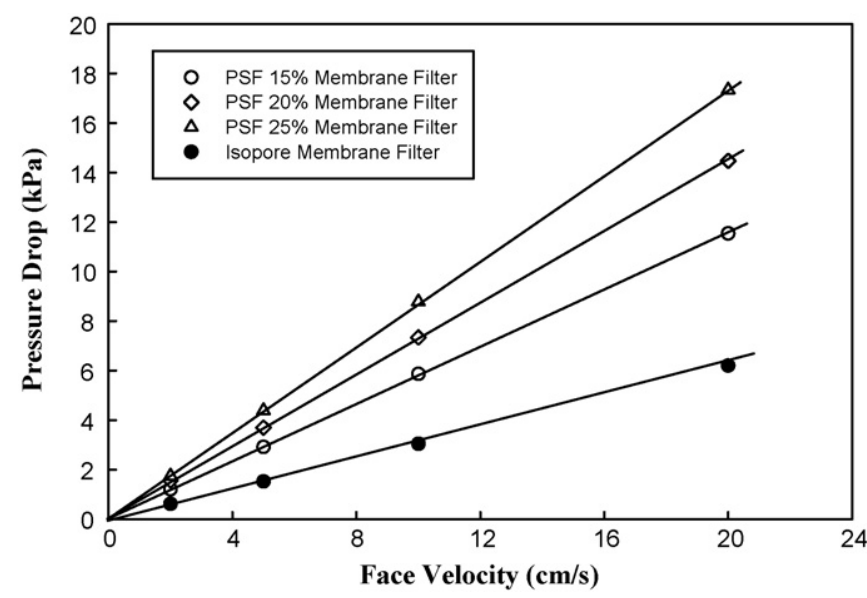

Fig. 3. Pressure drop across the PSF and manufactured capillary-pore membrane filters.

drops across the 15, 20 and 25\% PSF membrane filters are approximately $5.3,7.3$ and $8.7 \mathrm{kPa}$ at a face velocity of $10 \mathrm{~cm} / \mathrm{s}$. The pressure drop across the $25 \%$ PSF membrane filter exceeds that across the 15 and $20 \%$ PSF membrane filters, because the porosity of the $25 \%$ PSF membrane filter $(40.6 \%)$ is less than that of the 15 and $20 \%$ PSF membrane filters (48.4 and $55.9 \%$ ). At a flow rate of $10 \mathrm{~cm} / \mathrm{s}$, the pressure drop across the manufactured capillary-pore membrane filter is about $3.04 \mathrm{kPa}$. According to the comparison of the pressure drops across the three PSF membrane filters and manufactured capillary-pore membrane filter, the pressure drops across the PSF membrane filters are higher than that across the manufactured capillary-pore membrane filter.

\subsection{Penetration through the PSF membrane filters with liquid DOP aerosol}

This work used three different concentrations of casting solutions $(15,20$ and $25 \%)$ to product the three kinds of PSF membrane filters and explored the effects of the different concentration-casting solutions on the aerosol penetration. Fig. 4 plots the aerosol penetrations of "Boltzmann equilibrium"

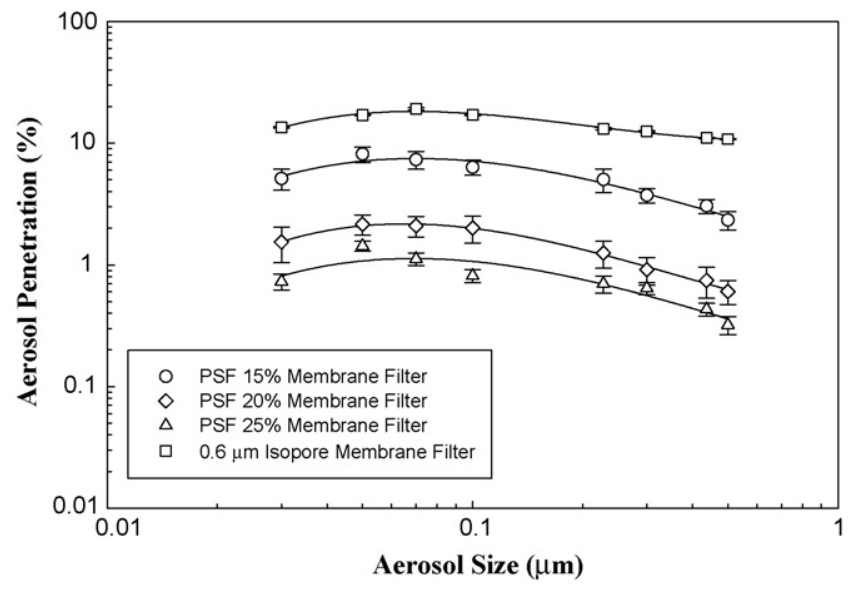

Fig. 4. Aerosol penetration through the PSF membrane filters and Isopore membrane filter at face velocity of $10 \mathrm{~cm} / \mathrm{s}$. 
DOP liquid aerosols through the 15, 20 and 25\% PSF membrane filters. In each test, the face velocity was controlled at $10 \mathrm{~cm} / \mathrm{s}$. At the whole range of testing aerosol sizes, the aerosol penetration through the 15, 20 and 25\% PSF membrane filters with "Boltzmann charge equilibrium" DOP liquid aerosols are around $3.1-9.1,1.5-3.7$ and $0.6-1.4 \%$, respectively. The experimental results in Fig. 4 indicate that the most penetrating aerosol size through the PSF membrane filters was approximately $0.05 \mu \mathrm{m}$. When aerosol is smaller than $0.05 \mu \mathrm{m}$, the Brown Diffusion effect is the main filtration mechanism in the filtration process. And the Brown Diffusion effect is getting weak with aerosol size increasing. However, when aerosol is larger than $0.05 \mu \mathrm{m}$, impaction and interception mechanisms, which are the main filtration mechanism of the PSF filtration process, become significant with aerosol size. Thus, when Brown Diffusion effect decrease and impaction and interception mechanisms increase, the penetration would reach a maximum and the most penetrating size is the $0.05 \mu \mathrm{m}$. That is the main reason that the most penetrating aerosol size was 0.05 um for three PSF membrane filters with different pore sizes.

Moreover, the aerosol penetrations through the 25\% PSF membrane filter are the lowest, the aerosol penetrations through the 20\% PSF membrane filter are the second, and the 15\% PSF membrane filter has the highest aerosol penetration over the total testing aerosol sizes. The main reason is that the pore size of the PSF membrane filter decreases as the PSF concentration of the casting solution increases. The principles of impaction and interception mechanic aerosol capturing forces are larger particles would deposit on the front face of membrane filter due to their inertia and particles would be captured when they contract the surface of the pore walls, respectively. The impaction and interception mechanic aerosol capturing forces increased as the size of the pores in the membrane filter dropped. Therefore, the aerosol penetration through the PSF membrane filter fell as the concentration-casting solution increased. Fig. 4 also plots the aerosol penetration through the manufactured capillarypore membrane filter against the aerosol size at a face velocity of $10 \mathrm{~cm} / \mathrm{s}$. The results demonstrate that the penetration through the manufactured capillary-pore membrane filter in the range of $10.8-19.0 \%$. According to the pervious investigations [10,21], the penetration through manufactured capillary-pore membrane filter is in the moderate penetration range. The penetration through the manufactured membrane is larger than that of these three PSF membrane filters. It is indicating that these three PSF filters have the better liquid aerosol penetration than the manufactured capillary-pore membrane filter.

However, the pressure drop across these three PSF membrane filters $(5.3,7.3$ and $8.7 \mathrm{kPa})$ is larger than that across the manufactured capillary-pore membrane filter $(3.04 \mathrm{kPa})$. A good filter has not only a high collection efficiency but also a low-pressure drop. Thus, this work used a quality factor $\left(q_{\mathrm{F}}\right)$, which is defined as the $\mathrm{Eq}(2)$, to further understand the performance of PSF membrane filters. The quality factor is a useful index of the filtration performance, which incorporates both the pressure drop and the aerosol penetration. A larger $q_{\mathrm{F}}$ corresponds to a better filter. Fig. 5 plots the $q_{\mathrm{F}}$ of the 15, 20 and 25\% PSF membrane filters, and manufactured capillary-pore membrane filter versus

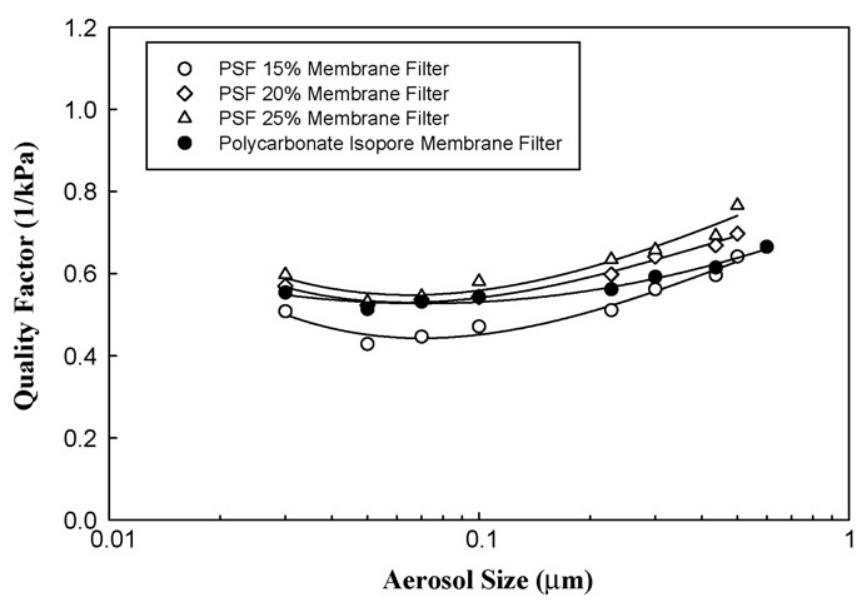

Fig. 5. Quality factor of the PSF and Isopore membrane filters at face velocity of $10 \mathrm{~cm} / \mathrm{s}$

the size of the aerosol at face velocity of $10 \mathrm{~cm} / \mathrm{s}$. The experimental data reveal that the 20 and 25\% PSF membrane filter has the larger $q_{\mathrm{F}}$ than the manufactured capillary-pore membrane filter over the entire range of aerosol sizes examined. It is suggesting that although the pressure drop across the 25 and $20 \%$ PSF membrane filters exceeds that across the manufactured capillary-pore membrane filter, the filtration performance of the PSF membrane filters is better. The pore size and penetration of the manufactured membrane filter belong to the moderate membrane filters. So we understood that some PSF membrane filters produced in laboratory could reach the moderate manufactured capillary-pore membrane filter. Furthermore, the experimental data show that the $25 \%$ PSF membrane filter has a larger $q_{\mathrm{F}}$ than the 15 and 20\% PSF membrane filters over the entire range of aerosol sizes examined. The $q_{\mathrm{F}}$ of the $20 \%$ PSF membrane filter is second and that of the $15 \%$ PSF membrane filter is lowest. Although the pressure drop across the 25\% PSF membrane filter is largest, the aerosol penetration through the $25 \%$ PSF membrane filter is sufficiently low to cause the $q_{\mathrm{F}}$ of the $25 \%$ PSF membrane filter to be the largest one.

\subsection{Effect of type of aerosol on aerosol penetration}

Fig. 6 plots the aerosol penetration through the 20\% PSF membrane filter against the size of the DOP liquid aerosols and the $\mathrm{KCl}$ solid aerosols at a face velocity of $10 \mathrm{~cm} / \mathrm{s}$. Experimental results indicate that the penetrations of DOP and $\mathrm{KCl}$ aerosols through the 20\% PSF membrane filters are almost identical. For instance, the maximum aerosol penetrations through the $20 \%$ PSF membrane of DOP and $\mathrm{KCl}$ aerosols are 3.6 and $4.5 \%$. Analogously, the penetrations through the $15 \%$ PSF membrane filters of the DOP and $\mathrm{KCl}$ aerosols are 9.1 and $10.2 \%$, and the penetrations through the $25 \%$ PSF membrane filters of the DOP and $\mathrm{KCl}$ aerosols are 1.4 and $2.2 \%$. The results reveal that the penetrations of the liquid aerosols through PSF membrane filters are slightly lower than that of solid aerosols. This finding is consistent with those of John et al. [22] which demonstrated that the penetration of liquid aerosols through the polycarbonate membrane filter exceeds that of solid aerosols because aerosol-bouncing effect 




Fig. 6. Aerosol penetration through the $20 \%$ PSF membrane filters against DOP and $\mathrm{KCl}$ aerosols at face velocity of $10 \mathrm{~cm} / \mathrm{s}$.

promotes the penetration of solid aerosols. The bouncing effect is probably the main reason why the penetration of solid aerosols through PSF membrane filters exceeds that of liquid aerosols.

\subsection{Effect of face velocity on aerosol penetration}

Fig. 7 plots the aerosol penetration through the 20\% PSF membrane filter versus the aerosol size, for the "Boltzmann charge equilibrium" DOP aerosol at various face velocities (5, 10 and $20 \mathrm{~cm} / \mathrm{s}$ ). The results shows an increase in the penetration of the $0.2-\mu \mathrm{m}$ aerosol through the $20 \%$ PSF membrane filter from around $2.4-9.4 \%$ as the face velocity rises from 5 to $20 \mathrm{~cm} / \mathrm{s}$. However, the $0.6-\mu \mathrm{m}$ aerosol penetrations through the $20 \%$ PSF membrane filter at face velocities of 5,10 and $20 \mathrm{~cm} / \mathrm{s}$ are $1.3,2.1$ and $2.5 \%$. Similar results are obtained for the 15 and $25 \%$ PSF membrane filter. The $0.2-\mu \mathrm{m}$ aerosol penetration through the $15 \%$ PSF membrane filter rises from 0.6 to $3.4 \%$ as face velocity rises from 5 to $20 \mathrm{~cm} / \mathrm{s}$; the $0.6-\mu \mathrm{m}$ aerosol penetrations through the $20 \%$ PSF membrane filter at face velocities of 5,10 and $20 \mathrm{~cm} / \mathrm{s}$ are $0.3,0.4$ and $0.4 \%$. That reveals that

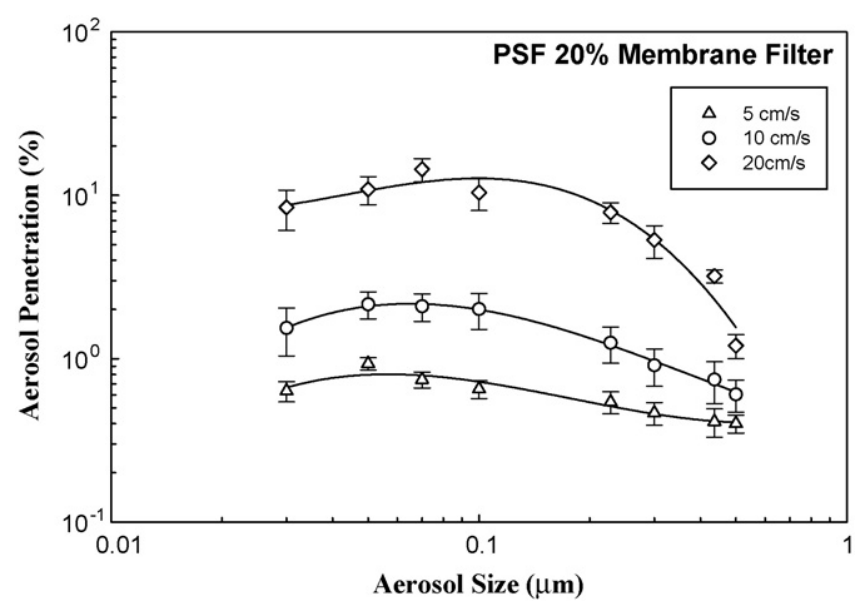

Fig. 7. Aerosol penetration through the $20 \%$ PSF membrane filters at different face velocities.



Fig. 8. Aerosol penetration through the $20 \%$ PSF membrane filters at different relative humidity.

aerosol penetration through the PSF membrane filters increases obviously with the face velocities from 5,10 and $20 \mathrm{~cm} / \mathrm{s}$ when aerosol smaller than $0.2 \mu \mathrm{m}$. When aerosol larger than $0.3 \mu \mathrm{m}$, the variation of penetration through the PSF membrane filters at different face velocity become smaller. It is due to that the diffusion effect works on the smaller aerosols $(<0.5 \mu \mathrm{m})$. A higher flow rate corresponds to a shorter residence time associated with aerosol deposition by diffusion. When aerosols are greater than $0.5 \mu \mathrm{m}$, the impaction and interception effects become obviously. The data are consistent with the results obtained by Liu et al. [25].

\subsection{Effect of relative humidity on aerosol penetration}

Fig. 8 plots the aerosol penetration through the $20 \%$ PSF membrane filter versus the aerosol size for three values of RH $(30,50$ and $70 \%)$. The experimental data indicate that the aerosol penetrations through the $20 \%$ PSF membrane filter at RH 30, 50 and $70 \%$ are almost the same. For instance, the $0.3-\mu \mathrm{m}$ aerosol penetrations through the $20 \%$ PSF membrane at RH values of 30,50 and $70 \%$ are $1.6,1.7$ and $1.7 \%$. Similarly, the aerosol penetrations through the 15 and $25 \%$ PSF membrane filters at three RH values are nearly identical, revealing that the RH does not affect the penetration of the aerosol through the PSF membrane filters.

\subsection{Comparison of the effect of different parameters on filtration performance}

A regression equation was used to understand the effects of different parameters on filtration performance of the PSF membrane filters. The penetration of solid and liquid aerosols was quite different, because aerosol-bouncing effect promotes the penetration of solid aerosols. Hence, the type of aerosol cannot be quantified nor regressed in the equation. The aerosol penetration is almost unaffected by the RH. Therefore, RH is also not regressed in the equation. The regression equation considered the most relevant parameters, including aerosol size $(0.03-0.5 \mu \mathrm{m})$, flow rate $(5-20 \mathrm{~cm} / \mathrm{s})$, and porosity of the 
membrane filter (55.9, 48.4 and $40.6 \%$ ). The experimental results can be fitted to the following equation.

$q_{\mathrm{F}}=a d_{\mathrm{p}}^{d} p^{c} u^{d}$

where $a, b, c$ and $d$ are constants, $q_{\mathrm{F}}$ is quality factor of the membrane filter, $d_{\mathrm{p}}$ is the aerosol size, $u$ is the flow rate and $p$ is porosity of the membrane filter. According to the regression analysis, the regression equation is shown as following:

$q_{\mathrm{F}}=0.65 d_{\mathrm{p}}^{0.113} p^{-0.128} u^{-0.025}$

As the results of regression analysis, the correlation coefficients $R^{2}$ is about 0.91 . Comparison of the coefficients of $b, c$ and $\mathrm{d}$, we found the effects of different parameters on the filtration performance. The result shows that the largest value is $c$, indicating the influence of the porosity of the membrane filter is the highest. The second value of the coefficient is $b$, and the smallest value is $d$. Thus, the effect of aerosol size on filtration performance is the second in the tested aerosol sized range. The effect of the flow rate on filtration performance is the lowest. The influence-degree of these three parameters only existed in the controlled condition of this work.

\section{Conclusions}

The penetrations of DOP liquid aerosols through the 15 , 20 and 25\% PSF membrane filters are 3.1-9.1, 1.5-3.7 and $0.6-1.4 \%$, respectively. The most penetrating size through PSF membrane filters is approximately $0.05 \mu \mathrm{m}$. The penetration of aerosol through the 25\% PSF membrane filter exceeds those through the 15 and 20\% PSF membrane filters, over the whole range of aerosol sizes, because the pores in the PSF membrane filter fall as the concentration of the casting PSF solution increases. The results also demonstrate that the penetration of solid aerosols through the PSF membrane filters exceeds that of liquid aerosols because of aerosol bouncing. The aerosol penetration through the PSF membrane filters increases obviously with the flow rate when aerosol smaller than $0.2 \mu \mathrm{m}$; when aerosol larger than $0.3 \mu \mathrm{m}$, the change of penetration through PSF membrane filters becomes smaller at different flow rate. The relative humidity does not affect the performance of the PSF membrane filters. The experimental data demonstrate that the $25 \%$ PSF membrane filter has a larger $q_{\mathrm{F}}$ than the 20 and $15 \%$ PSF membrane filters over the whole range of aerosol sizes. This work might also offer a new application for using PSF membrane filters in liquid aerosol filtration.

\section{Acknowledgement}

The authors would like to thank the National Science Council of Republic of China for financially supporting this research under Contract No. NSC 92-2218-E-041-006.

\section{References}

[1] G. Hoek, B. Forsberg, M. Borowska, S. Hlawiczka, E. Vaskovi, H. Welinder, M. Branis, I. Benes, F. Kotesovec, L.O. Hagen, J. Cyrys, M. Jantunen,
W. Roemer, B. Brunekreef, Wintertime PM10 and black smoke concentrations across Europe: results from the PEACE study, Atm. Environ. 31 (1997) 3341-3349.

[2] K. Saitoh, K. Serab, K. Hirano, T. Shirai, Chemical characterization of particles in winter-night smog in Tokyo, Atm. Environ. 36 (2001) 435-440.

[3] B.T. Mader, J.J. Schauer, J.H. Seinfeld, R.C. Flagan, J.Z. Yu, H. Yang, H.J. Lim, B.J. Turpin, J.T. Deminter, G. Heidemann, M.S. Bae, P. Quinn, T. Bates, D.J. Eatough, B.J. Huebert, T. Bertram, S. Howell, Sampling methods used for the collection of particle-phase organic and elemental carbon during ACE-Asia, Atm. Environ. 37 (2003) 1435-1449.

[4] O.F. Carvacho, T.N. Krystyna, L.L. Ashbaugh, R.G. Flocchini, P. Melin, J. Celisn, Elemental composition of springtime aerosol in Chillan, Chile. Atm. Environ. 38 (2004) 5349-5352.

[5] B.S. Cohen, S.V. Hering, Air Sampling Instruments for Evaluation of Atmospheric Contaminants, eighth ed., ACGIG, Cincinnati, 1995.

[6] K. Spurny, J. Pich, The separation of aerosol particles by means of membrane filters by diffusion and inertial impaction, Int. J. Air Water Pollut. 8 (1964) 193.

[7] M.J. Manton, The impaction of aerosols on a nuclepore filter, Atm. Environ. 12 (1978) 1669-1675.

[8] M.J. Manton, Brownian diffusion of aerosols to the face of a nuclepore filter, Atm. Environ. 13 (1979) 525-531.

[9] K.R. Spurny, J.P. Lodge, E.R. Frank, D.C. Sheesley, Aerosol filtration by means of nuclepore filters, structural and filtration properties, Environ. Sci. Technol. 3 (1969) 453-464.

[10] K.R. Spurny, J.P. Lodge, E.R. Frank, D.C. Sheesley, Aerosol filtration by means of nuclepore filters, aerosol sampling and measurement, Environ. Sci. Technol. 3 (1969) 464-468.

[11] M. Caroff, K.R. Choudhary, J.W. Gentry, Effect of pore and particle size distribution on efficiencies of membrane filters, J. Aerosol Sci. 4 (1973) 93-102.

[12] M. Smutek, J. Pich, Impaction of particles on the surface of membrane filters, J. Aerosol Sci. 5 (1974) 17-24.

[13] M. Montassier, L. Dupin, D. Boulaud, Experimental study on the collection efficiency of membrane filters, J. Aerosol Sci. 27 (Suppl. 1) (1996) S637-S638.

[14] C. Sioutas, P. Koutrakis, P.Y. Wang, P. Babich, M. Wolfson, Experimental investigation of pressure drop with particle loading in nuclepore filters, Aerosol Sci. Technol. 30 (1999) 71-83.

[15] N. Yamamoto, M. Fujii, K. Kumagai, Y. Yanagisawa, Time course shift in particle penetration characteristics through capillary pore membrane filters, J. Aerosol Sci. 35 (2004) 731-741.

[16] J.E. Kilduff, S. Mattaraj, J.P. Pieracci, G. Belfort, Photochemical modification of poly(ether sulfone) and sulfonated (polysulfone) nanofiltration membranes for control of fouling of natural organic matter, Desalination 132 (2000) 133.

[17] B. Kaeselev, J. Pieracci, G. Belfort, Photoinduced grafting of ultrafiltration membranes: comparison of poly(ether sulfone) and poly(sulfone), J. Membr. Sci. 194 (2001) 245.

[18] L. Liu, A. Chakma, X. Feng, Preparation of hollow fiber poly(ether block amide)/polysulfone composite membranes for separation of carbon dioxide from nitrogen, Chem. Eng. J. 105 (2004) 43-51.

[19] M. Yoshikawa, H. Hara, M. Tanigaki, M.D. Guiver, T. Matsuura, Modified polysulfone membranes 1. Pervaporation of water/alcohol mixtures through modified polysulphone membranes having methyl ester moiety, Polymer 33 (1992) 4805-4813.

[20] M.D. Guiver, G.P. Robertson, S. Rowe, S. Foley, Y.S. Kang, H.C. Park, J. Won, H.N.L. Thi, Modified polysulfones. IV. Synthesis and characterization of polymers with silicon substitutents for a comparative study of gas-transport properties, J. Polym. Sci. 39 (2001) 2103.

[21] B.H.Y. Liu, K.W. Lee, Efficiency of membrane and Nuclepore filters for submicronmeter aerosols, Environ. Sci. Technol. 10 (1976) 345-350.

[22] W. John, G. Reischl, S. Goren, D. Plotkin, Anomalous filtration of solid particles by Nuclepore Filters, Atmos. Environ. 12 (1978) 1555-1557.

[23] G.J. Summers, M.P. Ndawuni, C.A. Summers, Dipyridyl functionalized polysulfones for membrane production, J. Membr. Sci. 226 (2003) 21-33.

[24] Y. Xu, B. Zhu, Y. Xu, A study on formation of regular honeycomb pattern in polysulfone film, Polymer 46 (2004) 713-717. 
[25] B.H.Y. Liu, D.Y.H. Pui, K.L. Rubow, Characteristics of air sampling filter media, in: Aerosol in the Mining and Industrial Work Environment. III. Instrumentation., 1981, pp. 989-1038.

[26] T. Ito, Y. Otani, H. Inomata, Performance of air filters cleaned by supercritical carbon dioxide, Sep. Purif. Technol. 40 (2004) 41-46.

[27] W. Jasper, J. Hinestroza, A. Mohan, J. Kim, B. Shiels, M. Gunay, D. Thompson, R. Barker, Effect of xylene exposure on the performance of electret filter media, J. Aerosol Sci. 37 (2006) 903-911.
[28] E. Jankowska, H.T. Reponen, K. Willeke, S.A. Grinshpuns, K.J. Choi, Collection of fungal spores on air filters and spore reentrainment from filters into air, J. Aerosol Sci. 31 (2000) 969-978.

[29] ASHRAE, ANSI/ASHRAE Standard 52.2-1999. Method of testing general ventilation air-cleaning devices for removal efficiency by particle size, Society of Heating, Refrigerating, Air-conditioning Engineers, Inc., Atlanta, 1999.

[30] W.C. Hinds, Aerosol Technology, John Wiley and Sons, New York, 1982. 